\title{
EFFICACY AND SAFETY OF STANDARD VERSUS TUBELESS PERCUTANEOUS NEPHROLITHOTOMY- A RANDOMIZED CONTROLLED STUDY
}

\author{
Neelakandan Ramasamy¹, Jagadish Kaushik Balasubramanyan², Chandru Thirunavukarasu³, Natarajan Kumerasan", Goutham Reddy5
}

${ }^{1}$ Assistant Professor, Department of Urology, Sri Ramachandra Medical College and Research Institute, Chennai, Tamilnadu, India. 2Junior Resident, Department of Urology, Sri Ramachandra Medical College and Research Institute, Chennai, Tamilnadu, India. ${ }^{3}$ Professor, Department of Urology, Sri Ramachandra Medical College and Research Institute, Chennai, Tamilnadu, India. 4 Professor, Department of Urology, Sri Ramachandra Medical College and Research Institute, Chennai, Tamilnadu, India. 5Junior Resident, Department of Urology, Sri Ramachandra Medical College and Research Institute, Chennai, Tamilnadu, India.

\section{ABSTRACT}

\section{BACKGROUND}

Nephrolithiasis is a common urological disorder. PCNL is indicated for renal calculi $>2 \mathrm{~cm}$ in size. We present a prospective study to assess the efficacy and safety of tubeless PCNL in comparison to standard PCNL.

\section{METHODS}

A randomized control trial study was conducted in Sri Rama Chandra Medical Centre, Chennai, over a period of 2 years (i.e., between February 2016 to March 2018). A total of 220 patients were divided equally into two groups and were randomised into: Group A (undergoing tubeless PCNL; $\mathrm{n}=110$ ) and Group B (undergoing standard PCNL; $\mathrm{n}=110$ ). Factors that were evaluated included operative time, hospital stay, drop in haemoglobin, blood transfusion required, analgesics required, ancillary proce dure performed, stone clearance and complications. The qualitative variables were analysed by chi-square test and quantitative variables were analysed by the student's t test. A p-value $<0.05$ was considered as statistically significant.

\section{RESULTS}

There was no statistically significant difference between the two study groups for patient age, gender, stone location, associated stone disorders, and co-morbidities. Majority of the study participants were male i.e., $56.4 \%$ in Group A and $55.5 \%$ in Group B. The mean age in group A was $42.45 \pm 14.13$ years and in group B was $45.44 \pm 12.12$ years. There was statistically significant less operative time, less hospital stay, smaller drop in haemoglobin and less analgesic requirement in Group A (p-value < 0.0001) as compared to Group B. There was no significant difference between the study groups with respect to stone clearance, complications, requirement of blood transfusion and ancillary procedures performed.

\section{CONCLUSIONS}

The present study proves the advantages of tubeless PCNL. It has significantly less operative time, short hospital stays, less drop-in haemoglobin and less requirement of postoperative analgesic in comparison with standard PCNL. Thus, tubeless PCNL is effective and safe in selected group of individuals.

\section{KEY WORDS}

Nephrolithiasis, Nephrostomy Tube, Standard Percutaneous Nephrolithotomy, Tubeless Percutaneous Nephrolithotomy, Ureteral Stent

HOW TO CITE THIS ARTICLE: Ramasamy N, Balasubramanyan JK, Thirunavukarasu C, et al. Efficacy and safety of standard versus tubeless percutaneous nephrolithotomy- a randomized controlled study. J. Evolution Med. Dent. Sci. 2019;8(25):2002-2006, DOI: $10.14260 /$ jemds/2019/440

\section{BACKGROUND}

Nephrolithiasis is one of the most common urological conditions. In fact, current data establishes its prevalence in the United States population at $10.6 \%$ for adult male and 7.1 $\%$ for adult female.[1] Though historically, urinary calculi had high prevalence in male gender, but recently its incidence rate ratio of adult male to female has come down from 3.4 to 1.3.[2] Urinary calculi is usually a recurring and lifelong disease, forecasting even greater recurrence rates and

'Financial or Other Competing Interest': None.

Submission 03-04-2019, Peer Review 07-06-2019,

Acceptance 14-06-2019, Published 24-06-2019.

Corresponding Author:

Neelakandan Ramasamy,

Assistant Professor,

E2 Urology OPD,

Ramachandra Medical Centre,

Porur, Chennai-600116, Tamilnadu, India.

E-mail:dr.neelakandan@gmail.com

DOI: $10.14260 /$ jemds $/ 2019 / 440$ dreadful clinical outcomes in the later part of life and thus, culminating in significantly higher economic burden. ${ }^{[3]}$ White population are commonly affected than Asians and AfroAmericans. There is also greater prevalence with advancing age.[1]

Various methods for the treatment for nephrolithiasis range from non-invasive to invasive and includes medicinal treatment, extracorporeal shock wave lithotripsy (ESWL), percutaneous nephrolithotomy (PCNL), and open renal surgery. ${ }^{[4,5]}$ PCNL was first demonstrated in 1976 by Fernstrom and Johansson and in the last two decades, it has become a preferred therapy for extracting a large and complex renal stone.[6,7]

Standard PCNL procedure includes placement of a nephrostomy tube at the completion of the procedure and while, some urologists also practice insertion of ureteral stent for internal drainage. Advantages associated with nephrostomy tube includes haemostasis along the tract, avoiding urinary extravasation, and maintain adequate drainage of the kidney, but the tube is also associated with 
disadvantages such as an increased hospital stay and more analgesic requirement. Tubeless PCNL is PCNL without postoperative nephrostomy tube placement. It was in 1997, when Bellman first demonstrated tubeless PCNL. Since then, the urologist has tried to modify this procedure with interest and enthusiasm, leading to its widespread use.[8] The efficacy and safety of this procedure has been reported in several prospective randomized controlled studies, systematic reviews and meta-analysis. These studies have also demonstrated that the length of hospital stay, use of analgesics, pain profiles, and indirectly cost are significantly lower in patients undergoing the tubeless PCNL procedure.[9-16] In the present study, we aimed to prospectively compare the efficacy and safety of the standard and tubeless PCNL, with special focus on feasibility, operative time, postoperative pain, complications and length of hospital stay.

\section{METHODS}

A Randomized control trial study total of 220 patients with nephrolithiasis underwent PCNL in our hospital between February 2016 to March 2018. Patients are divided equally into two groups - Group A (110 cases of tubeless PCNL) and Group B (110 cases of standard PCNL). The groups had no differences between operation technique- including dilatation size and type. Sample size was taken for convenience. This 220 Patients were randomized using computer generated random numbers and allocated into two groups into Group A and Group.

Inclusion criteria were stone $>2 \mathrm{~cm}$ in size (Who underwent PCNL as primary procedure); single puncture tract; procedure lasting less than $2 \mathrm{hrs}$.; less than three stones with a diameter $<25 \mathrm{~mm}$; complete extraction of all stones; and no significant bleeding at the end of the procedure. Whereas, exclusion criteria included residual calculi; significant bleeding at the end of procedure and multiple puncture tract.

All patients were evaluated with physical examination, urine analysis, urine culture and sensitivity, complete blood count, renal function test, X-ray KUB, and non-contrast CT. Patients with urinary tract infections (UTI) were treated with antibiotics and operation was performed after sterile urine cultures.

\section{Statistical Analysis}

All statistical analysis was performed using SPSS (version 17) for Microsoft Windows. Descriptive statistics were presented as numbers and percentages. The data were expressed as Mean \pm SD. Independent sample student $t$ test were used to compare continuous variables between two groups. A chisquared test was used for comparison categorical variables between two groups. A two-sided p-value $<0.05$ was considered statistically significant.

\section{RESULTS}

In the present study, there were no drop-outs. Thus, all 110 patients in each group were evaluated. Majority of the study population in both the groups included male gender, with male: female ratio of 1.29:1 and 1.24:1 in Group A and Group $B$, respectively. There was no statistically significant difference among demographic variables in both the groups (Table 1).

\begin{tabular}{|c|c|c|c|}
\hline Variables & Group A $(n=110)$ & Group B $(n=110)$ & p-Value \\
\hline Age (Years) & $42.45 \pm 14.13$ & $45.44 \pm 12.12$ & $0.094^{\#}$ \\
\hline \multirow{2}{*}{$\begin{array}{c}\text { Gender Male (\%) } \\
\text { Female }(\%)\end{array}$} & $62(56.4 \%)$ & $61(55.5 \%)$ & \multirow[b]{2}{*}{$0.892^{\$}$} \\
\hline & $48(43.6 \%)$ & $49(44.5 \%)$ & \\
\hline \multicolumn{4}{|c|}{ Table 1. Demographic Variables of Both the Groups } \\
\hline \multicolumn{4}{|c|}{$\begin{array}{l}\text { Data expressed as absolute number, percentage and mean } \pm \text { SD; SD- } \\
\text { Standard deviation; \# - Unpaired t-test; } \$ \text { - Chi-square test; p-value } \\
<0.05 \text { was considered as statistically significant. }\end{array}$} \\
\hline
\end{tabular}

\begin{tabular}{|c|c|c|c|}
\hline Variables & $\begin{array}{c}\text { Group A } \\
(\mathrm{n}=110)\end{array}$ & $\begin{array}{c}\text { Group B } \\
(\mathrm{n}=110)\end{array}$ & p-Value \\
\hline Sr. creatinine $(\mathrm{mg} / \mathrm{dl})$ & $1.098 \pm 0.429$ & $1.020 \pm 0.468$ & $0.198^{\#}$ \\
\hline \multicolumn{4}{|c|}{ Laterality } \\
\hline Left (\%) & $57(51.8 \%)$ & $61(55.5 \%)$ & \multirow[b]{2}{*}{$0.589^{\$}$} \\
\hline Right (\%) & $53(48.2 \%)$ & $49(44.5 \%)$ & \\
\hline \multicolumn{4}{|c|}{ Co-morbidities } \\
\hline Hypertension (\%) & $10(9.1 \%)$ & $14(12.7 \%)$ & $0.387^{\$}$ \\
\hline Diabetes mellitus (\%) & $21(19.1 \%)$ & $19(17.3 \%)$ & $0.727^{\$}$ \\
\hline \multicolumn{4}{|c|}{$\begin{array}{c}\text { Associated Stone Disease } \\
\end{array}$} \\
\hline Ureteric stone (\%) & $9(8.2 \%)$ & $7(6.4 \%)$ & \multirow[b]{2}{*}{$0.353^{\$}$} \\
\hline $\begin{array}{c}\text { Opposite kidney stone } \\
(\%)\end{array}$ & $11(10 \%)$ & $18(16.4 \%)$ & \\
\hline \multicolumn{4}{|c|}{ Table 2. Preoperative Variables of Both the Groups } \\
\hline \multicolumn{4}{|c|}{$\begin{array}{l}\text { Data expressed as absolute number, percentage and mean } \pm \text { SD; SD- } \\
\text { Standard deviation; \# - Unpaired t-test; } \$ \text { - Chi-square test; p-value < } \\
0.05 \text { was considered as statistically significant. }\end{array}$} \\
\hline
\end{tabular}

\begin{tabular}{|c|c|c|c|}
\hline Variables & $\begin{array}{c}\text { Group A } \\
(\mathrm{n}=110)\end{array}$ & $\begin{array}{c}\text { Group B } \\
(\mathrm{n}=110)\end{array}$ & p-Value \\
\hline OT time (minutes) & $62.06 \pm 12.89$ & $72.22 \pm 17.55$ & $<0.0001^{\#}$ \\
\hline \multicolumn{4}{|c|}{ Puncture Site } \\
\hline Inferior calyx (\%) & 76 (69.1\%) & $85(77.3 \%)$ & \multirow{3}{*}{$0.138^{\$}$} \\
\hline Middle calyx (\%) & & & \\
\hline Superior calyx (\%) & $10(9.1 \%)$ & $12(10.9 \%)$ & \\
\hline \multicolumn{4}{|c|}{ Table 3. Intraoperative Variables of Both the Groups } \\
\hline \multicolumn{4}{|c|}{$\begin{array}{l}\text { Data expressed as absolute number, percentage and mean } \pm \text { SD; SD- } \\
\text { Standard deviation; \# - Unpaired t-test; } \$ \text { - Chi-square test; p-value < } \\
0.05 \text { was considered as statistically significant }\end{array}$} \\
\hline
\end{tabular}

\begin{tabular}{|c|c|c|c|}
\hline Variables & $\begin{array}{c}\text { Group A } \\
(\mathrm{n}=110)\end{array}$ & $\begin{array}{c}\text { Group B } \\
(\mathrm{n}=\mathbf{1 1 0})\end{array}$ & p-Value \\
\hline Drop in $\mathrm{Hb}(\mathrm{gm} \%)$ & $0.98 \pm 0.168$ & $1.187 \pm 0.382$ & $<0.0001^{\#}$ \\
\hline Analgesic requirement (gm) & $236.55 \pm 53.294$ & $350.99 \pm 55.175$ & $<0.0001^{\#}$ \\
\hline Hospital stay (days) & $2.78 \pm 0.932$ & $3.9 \pm 1.292$ & $<0.0001^{\#}$ \\
\hline \multicolumn{4}{|c|}{ Stone Clearance } \\
\hline Complete (\%) & $107(97.3 \%)$ & $105(95.5 \%)$ & \multirow[b]{2}{*}{$0.471^{\$}$} \\
\hline Incomplete (\%) & $3(2.7 \%)$ & $5(4.5 \%)$ & \\
\hline \multicolumn{4}{|c|}{ Ancillary Procedure } \\
\hline ESWL (\%) & $6(5.5 \%)$ & $9(8.2 \%)$ & \multirow{3}{*}{$0.652^{\$}$} \\
\hline URS (\%) & $9(8.2 \%)$ & $7(6.4 \%)$ & \\
\hline No complications (\%) & $95(86.4 \%)$ & $94(85.5 \%)$ & \\
\hline \multicolumn{4}{|c|}{ Complications } \\
\hline Bleeding & $7(6.4 \%)$ & $5(4.5 \%)$ & \multirow{3}{*}{$0.480^{\$}$} \\
\hline Urosepsis & $9(8.2 \%)$ & $14(12.7 \%)$ & \\
\hline No complication & $94(85.5 \%)$ & $91(82.7 \%)$ & \\
\hline \multicolumn{4}{|c|}{ Table 4. Postoperative Variables of Both the Groups } \\
\hline \multicolumn{4}{|c|}{$\begin{array}{l}\text { Data expressed as absolute number, percentage and mean } \pm \text { SD; SD- } \\
\text { Standard deviation; ESWL- Extracorporeal shock wave lithotripsy; URS- } \\
\text { Ureteroscopy; \# - Unpaired t-test; } \$ \text { - Chi-square test; } p \text {-value }<0.05 \text { was } \\
\text { considered as statistically significant. }\end{array}$} \\
\hline
\end{tabular}

Preoperative variable in both the study groups are summarised in Table 2. Mean serum creatinine, laterality index, and co-morbidities like hypertension and diabetes mellitus were not significantly different in both the groups.

Intraoperative variables in both the study groups are depicted in Table 3. Mean operation time was higher in Group B and it was found to be statistically significant ( $p$ value $<0.0001)$. While, inferior calyx was the puncture site in majority of the study population in both the groups, but these puncture sites were not found to be significantly different ( $\mathrm{p}$ value $=0.138$ ). 
Postoperative variables in both the study groups are mentioned in Table 4. Mean decline in haemoglobin ( $\mathrm{p}$-value $<0.0001$ ), mean analgesic requirement ( $p$-value $<0.0001$ ) and mean duration of hospital stay ( $\mathrm{p}$-value $<0.0001$ ) were found to be significantly higher in Group B. Majority of the patients had stone clearance i.e., 97.3\% in Group A and 95.5 $\%$ in Group B. Bleeding as a complication was observed in 7 patients of Group A and 5 patients of Group B. Whereas, urosepsis was reported in 9 patients of Group A and 14 patients of Group B. But there was no significant difference in the operative complications among the study groups ( $\mathrm{p}$-value $=0.480$ ). These complications were managed conservatively. Finally, there was no significant difference between the study groups in ancillary procedures performed ( $\mathrm{p}$-value $=0.652$ ). Wherein, 6 patients of Group A and 9 patients of Group B underwent ESWL and 9 patients of Group A and 7 patients of Group B underwent URS.

\section{Surgical Technique}

All patients underwent PCNL under general anaesthesia. Patients were placed in lithotomy position and a 6 Fr ureteric catheter was introduced. Contrast was used to identify the collecting system and to select the calyx for puncture.

After prone positioning with adequate padding, posterior calyceal puncture was done under fluoroscopic guidance. Level of puncture was decided as per location of stone to ensure complete clearance.

Puncture was done using 18 G two-part needle and guide-wire was placed within the system. Guide-rod was introduced, and serial coaxial dilatation of tract done with Alkens metal dilator. Amplatz's heath was placed. Using 20.8 Fr Karl Storz nephroscope and Karl Storz pneumatic lithotripter stone fragmentation was done.

After fragments were evacuated, antegrade 6 Fr ureteric stent was placed in group A and skin incision sutured and compression bandage applied. A $20 \mathrm{Fr}$ nephrostomy tube along with 6 Fr ureteric stent was placed in patients coming under group B.

\section{Variables}

Preoperative parameters like stone size, stone disease in the opposite kidney and ureter, preoperative serum creatinine, and associated co-morbidities were recorded. Intraoperative parameters like operative time, access tract and the need for blood transfusion were recorded. Patients were followed up in postoperative period with decrease in $\mathrm{Hb}$, need for blood transfusion, need for analgesia, hospital stay, complications and need for ancillary procedure. In group B, post-procedure X-ray KUB was performed before removing the nephrostomy tube on the first postoperative day. In both group, ureteric stent was removed after 14 days.

Thus, stone size, preoperative serum creatinine, operative time, stone clearance rate, length of hospital stay, analgesic requirements, and postoperative complications such as bleeding, infection or ureteral obstruction were recorded and compared.

\section{DISCUSSION}

American Urological Association (AUA) recommends PCNL for kidney stones $>2 \mathrm{~cm}$ in size. It provides a higher stonefree rate than SWL or URS and is less invasive than open surgery or laparoscopic/ robotic assisted procedures.
Moreover, the success rate of PCNL is less dependent on composition, density and location of the stone.[17] Historically, the procedure followed includes leaving a temporary nephrostomy tubes of varying calibre and type in place at the end of PCNL procedures for variety of reasons such as drainage, tamponade of bleeding and to permit second-look procedures.[6,18] Tubeless PCNL wherein only an internal ureteral stent is used, has been claimed to have less morbidity and early recovery when compared to a standard PCNL. [8,9,11,16]

In the present study, there was no statistically significant difference between the study groups in terms of the age and gender of the patients, stone side (i.e., left or right) and location (i.e., ureter or opposite kidney), comorbidities such as hypertension and diabetes mellitus, and serum creatinine; thus minimising their effect on the outcomes of the procedures.

In the present study, majority of patients in both the group were males (56 \% in Group A and $55 \%$ in Group B). This finding is in accordance with the previous studies, which reported that male gender has higher prevalence of nephrolithiasis.[1,19,20] In the present study, mean age of patients in group A was 42.45 years and 45.44 years. Various studies have reported similar findings.[21,22] The cause of higher prevalence in middle-age population may be due to more laborious work performed by them relative to others, and thus, resulting in less fluid intake and greater rate of dehydration.[23]

In the present study, comorbidities like hypertension and diabetes mellitus (DM) were reported in $9.1 \%$ and $19.1 \%$ patients in Group A and $12.7 \%$ and $17.3 \%$ patients in Group $\mathrm{B}$, respectively. While, occurrence of uric acid stone shows positive correlation with $\mathrm{DM}$, the evidence for the association between hypertension and nephrolithiasis has been inconsistent. Lower urinary $\mathrm{pH}$ due to the effects of insulin resistance on ammoniagenesis has been described as reason for positive correlation between DM and nephrolithiasis.[24]

In the present study, time taken for procedure was statistically more in Group B as compared to Group A (pvalue $<0.0001$ ). Contrary to the present study, Nalbant I et al.[11]and Gupta NP et al.[25]reported slightly longer operative time for standard PCNL as compared to tubeless PCNL, but there was no significant difference ( $p$-value $>0.05)$. While, recent meta-analysis by Xun $Y$ et al.[16] reported that tubeless PCNL was significantly associated with shorter operative time ( $p$-value $=0.012$ ). Thus, supporting the findings of the present study. These differences in operative times cited in literature might be due to the different criteria used to calculate operative time. Moreover, important determinants of total operative time are patient characteristics and surgeon's experience.

In the present study, mean hospital stay and mean amount of analgesic required (Tramadol) was found to be significantly less in patients of Group A compared to Group B (p-value < 0.0001). Similarly, Agarwal MS et al.[18] and Gupta NP et al.[25]demonstrated significantly less mean hospital stay and mean amount of analgesic required in patients with tubeless PCNL as compared to standard PCNL. While, Nalbant I et al.[11] and Sebaey A et al.[26] reported only significantly decreased mean hospital stay and mean amount of analgesic required, respectively in patients with tubeless PCNL as compared to standard PCNL. As tubeless PCNL does not 
require use of nephrostomy tube and thus, less postoperative pain and discomfort. Resulting in short hospital stay and less use of analgesics. Moreover, the standard PCNL procedure requires an additional procedure for tube removal, leading to more use of analgesics and further increasing the hospital stay.

Post-operative drop in haemoglobin finds its mention in the literature. To determine the patients who may have had more significant intraoperative bleeding, and thus, may be at greater risk of post-operative bleeding, we used the immediate post-operative drop in haemoglobin. In the present study, mean decrease in haemoglobin was significantly higher in Group B (p-value $<0.0001$ ) as compared to Group A, but there was no significant difference between the study groups for the number of patients who required blood transfusion. Thus, suggesting that in patients with moderate intraoperative bleeding the tubeless PCNL is safe. But, there was no significant difference between tubeless and standard PCNL for mean decrease in haemoglobin and blood transfusion rate as per the studies by Xun Y et al.[16] and Agarwal MS et al..[18] Though the drop in haemoglobin may not be associated with the use of a nephrostomy tube.

In the present study, there was no significant difference in the operative complications like urosepsis and bleeding ( $\mathrm{p}$-value $=0.480)$.Similarly, Isac $\mathrm{W}$ et al. reported no significant difference between tubeless and standard PCNL regarding the complications. In the present study, requirement of ancillary procedures (i.e., ESWL and URS) was not statistically significant $(p$-value $=0.652$ ) between the study groups. Sofikerim Met al.[27] performed only ESWL as ancillary procedures, $8.3 \%$ for standard and $4.2 \%$ for tubeless groups. In a study by Shah $\mathrm{H}$ et al.[28] the majority of ancillary procedures were extra corporeal shock wave lithotripsy (ESWL) (18 in tubed group and 19 in tubeless group).

Moreover, in the present study, there was no significant difference in between both the groups for stone clearance ( $p$ value $=0.471$ ). Amer Tet al.[10] reported no significant difference in stone clearance between tubeless and standard PCNL. With PCNL, at the completion of the procedure, it is sometimes difficult to eliminate the presence of residual stones. Thus, in certain patients, carrying out an additional puncture tract may sometimes be inevitable.

Limitations of the present study includes nonrandomised nature of the study (Thus, leading to selection bias), size of stone was not evaluated, and pre- and postoperative pain scores were not calculated.

\section{CONCLUSIONS}

Tubeless PCNL is effective and safe alternative to standard PCNL, in a cautiously selected group of patients. When compared to standard PCNL, tubeless PCNL has significantly shorter hospital stay, less operative time, less decrease in haemoglobin, less requirement of analgesics, shorter hospital stay which indirectly leads to reduction of healthcare cost. In the near future, with expertise and further decline in morbidity, tubeless PCNL may become a day-care procedure in a selected group of patients.

\section{REFERENCES}

[1] Scales CD Jr, Smith AC, Hanley JM, et al. Prevalence of kidney stones in the United States. Eur Urol 2012;62(1):160-5.

[2] Strope SA, Wolf JS Jr, Hollenbeck BK. Changes in gender distribution of urinary stone disease. Urology 2010;75(3):543-6.

[3] Zisman AL. Effectiveness of treatment modalities on kidney stone recurrence. Clin J Am Soc Nephrol 2017;12(10):1699-708.

[4] Pearle MS, Goldfarb DS, Assimos DG, et al. Medical management of kidney stones: American Urological Association (AUA) J Urol 2014;192(2):316-24.

[5] Assimos D, Krambeck A, Miller NL, et al. Surgical management of stones: American Urological Association/Endourological Society Guideline, Part I. J Urol 2016;196(4):1153-60.

[6] Fernström I, Johansson B. Percutaneous pyelolithotomy. A new extraction technique. Scand J Urol Nephrol 1976;10(3):257-9.

[7] Geraghty R, Jones P, Somani BK, et al. Worldwide trends of urinary stone disease treatment over the last two decades: a systematic review. J Endourol 2017;31(6):547-56.

[8] Bellman GC, Davidoff R, Candela J, et al. Tubeless percutaneous renal surgery. J Urol 1997;157(5):157882.

[9] Yuan H, Zheng S, Liu L, et al. The efficacy and safety of tubeless percutaneous nephrolithotomy: a systematic review and meta-analysis. Urol Res 2011;39(5):40110.

[10] Amer T, Ahmed K, Bultitude M, et al. Standard versus tubeless percutaneous nephrolithotomy: a systematic review. Urol Int 2012;88(4):373-82.

[11] Nalbant I, Ozturk U, Sener NC, et al. The comparison of standard and tubeless percutaneous nephrolithotomy procedures. Int Braz J Urol 2012;38(6):795-801.

[12] Karadag MA, Cecen K, Demir A, et al. Tubeless percutaneous nephrolithotomy: can be a choice, why not? The Open Urology \& Nephrology Journal 2014;7:4-7.

[13] Isac W, Rizkala E, Liu X, et al. Tubeless percutaneous nephrolithotomy: outcomes with expanded indications. Int Braz J Urol 2014;40(2):204-11.

[14] Abbott JE, Deem SG, Mosley N, et al. Are we fearful of tubeless percutaneous nephrolithotomy? Assessing the need for tube drainage following percutaneous nephrolithotomy. Urol Ann 2016;8(1):70-5.

[15] Lai W, Jou YC, Cheng MC, et al. Tubeless percutaneous nephrolithotomy: experience of 1000 cases at a single institute. Urological Science 2017;28(1):23-6.

[16] Xun Y, Wang Q, Hu H, et al. Tubeless versus standard percutaneous nephrolithotomy: an update metaanalysis. BMC Urology 2017;17(1):102.

[17] Assimos D, Krambeck A, Miller NL, et al. Surgical management of stones: American Urological Association/ Endourological Society Guideline, Part II. J Urol 2016;196(4):1161-9.

[18] Agarwal MS, Agarwal M, Gupta A, et al. A randomized comparison of tubeless and standard percutaneous nephrolithotomy. J Endourol 2008;22(3):439-42. 
[19] Zeng Q, He Y. Age-specific prevalence of kidney stones in Chinese urban inhabitants. Urolithiasis 2013;41(1):91-3.

[20] Sharma S, Chaudhari R, Rawal K, et al. Low dose computed tomography KUB region for management of urolithiasis in Indian scenario. Int Surg J 2018;5(2):638-42.

[21] Kohri K, Ishikawa Y, Katoh Y, et al. Epidemiology of urolithiasis in the elderly. Int Urol Nephrol 1991;23(5):413-21.

[22] Kolhe SP, Bhamre SD. Clinical profile of patients with renal calculi in a tertiary care centre. MVP Journal of Medical Sciences 2017;4(2):126-34.

[23] Kale SS, Ghole VS, Pawar NJ, et al. Inter-annual variability of urolithiasis epidemic from semi-arid part of Deccan Volcanic Province, India: climatic and hydrogeochemical perspectives. Int J Environ Health Res 2014;24(3):278-89.
[24] Sorokin I, Mamoulakis C, Miyazawa K, et al. Epidemiology of stone disease across the world. World J Urol 2017;35(9):1301-20.

[25] Gupta NP, Mishra S, Suryawanshi M, et al. Comparison of standard with tubeless percutaneous nephrolithotomy. J Endourol 2008;22(7):1441-6.

[26] Sebaey A, Khalil MM, Soliman T, et al. Standard versus tubeless mini-percutaneous nephrolithotomy: a randomised controlled trial. Arab Journal of Urology 2016;14(1):18-23.

[27] Sofikerim M, Demirci D, Huri E, et al. Tubeless percutaneous nephrolithotomy: safe even in supracostal access. J Endourol 2007;21(9):967-72.

[28] Shah H, Khandkar A, Sodha H, et al. Tubeless percutaneous nephrolithotomy: 3 years of experience with 454 patients. BJU Int 2009;104(6):840-6. 